\title{
Investigate earing of TWIP steel sheet during deep-drawing process by using crystal plasticity constitutive model
}

\author{
J. Yang, Y. Cai, C.Y. Sun a , B. Wang, and X.R. Guo \\ School of Mechanical Engineering, University of Science and Technology, Beijing, China
}

\begin{abstract}
By combining the nonlinear finite element analysis techniques and crystal plasticity theory, the macroscopic mechanical behaviour of crystalline material, the texture evolution and earing-type characteristics are simulated accurately. In this work, a crystal plasticity model exhibiting deformation twinning is introduced based on crystal plasticity theory and saturation-type hardening laws for FCC metal Fe-22Mn-0.6C TWIP steel. Based on the CPFE model and parameters which have been determined for TWIP steel, a simplified finite element model for deep drawing is promoted by using crystal plasticity constitutive model. The earing characteristics in typical deep-drawing process are simulated well. Further, the drawing forces are calculated and compared to the experimental results from reference. Meanwhile, the impacts of drawing coefficient and initial texture on the earing characteristics are investigated for controlling the earing.
\end{abstract}

\section{Introduction}

With the rise of automobile industry in recent years, more demands and higher standards are set for it out of the great importance attached to environmental protection and energy saving, including lower fuel consumption and higher security. According to statistics, fuel consumption can be reduced by $0.6 \%$ to $1 \%$ with $1 \%$ reduction in car weight. So the lightweight of automobile is an important way to cut down oil consumption [1].

In 1998, Grassel [2] discovered the TWIP (Twinning induced plasticity) effect of Fe-Mn-Si-Al steel, and named it TWIP steel. TWIP steel has been studied as one kind of high strength steels for its high strength and considerable elongation. The application of TWIP steel on the automobile can improve the impact resistance and achieve the lightweight of automobile without weakening mechanical property.

Deformation twinning appears in the plastic deformation process which contains two mechanisms of slipping and twinning $[3,4]$. Under the effect of shear stress, dislocation slips along the slip plane. When it is blocked, deformation twinning appears along the twinning direction at twinning plane, and when the twinning crystal increases to a certain amount, the crystal orientation changes, which is good for crystal slipping. For a better understanding on the effect of slip and twinning during plastic deformation of TWIP steel, the research on twinning and slipping mechanism of TWIP steel under crystal plasticity constitutive relation model has become the focus in recent years [5].

\footnotetext{
${ }^{\text {a }}$ Corresponding author: suncy@ustb.edu.cn
}

This is an Open Access article distributed under the terms of the Creative Commons Attribution License 4.0, which permits unrestricted use, distribution, and reproduction in any medium, provided the original work is properly cited. 


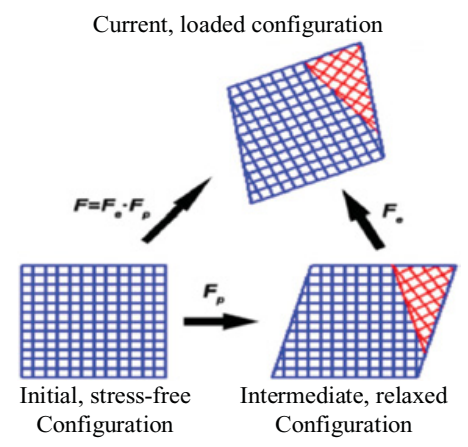

Figure 1. The multiplicative decomposition of deformation gradient with twinning contained.

The crystal plasticity theory is based on the theory of dislocation slipping, which mainly examines the function of slipping in plastic deformation [6]. Further, the twinning mechanism are also introduced into the crystal plasticity constitutive model by Houte [7] and Kalidindi [8] for a more precise description of the plastic deformation behaviour of some metals, such as hadifield steel [5] and $\alpha$-Ti [9]. In the study of crystal plasticity, most scholars focus on polycrystalline model and macroscopic mechanical behaviour, while loading experiment on $\mathrm{Cu}$ was performed at the temperature of $4.2 \mathrm{~K}$ by Niewczas [10], and the mutation phenomenon of stress appeared, which is hard to explain directly.

In this paper, the crystal plasticity constitutive relation of single crystal and polycrystal is developed based on the crystal plasticity theory and polycrystalline homogenization method, and the crystal plasticity finite element (CPFE) model based on the UMAT is built to simulate the typical deep-drawing process of earing making. And then, the impact of drawing coefficient and initial texture on the erringtype, earing ratio and drawing forces is discussed to get corresponding conclusions.

\section{CPFE model and the deep-drawing process of TWIP steel}

\subsection{Single crystal plasticity constitutive model of TWIP steel with twinning coupled}

Based on the crystal plasticity theory, slipping is the main cause of plastic deformation which includes the dislocation slip and rotation. In order to take the effect of twinning into consideration, twinning is contained into the multiplicative decomposition of deformation gradient, which is shown in Eq. (1) and Fig. 1 [9].

$$
\boldsymbol{F}=\boldsymbol{F}_{\mathrm{e}} \cdot \boldsymbol{F}_{\mathrm{p}}
$$

Where $\boldsymbol{F}_{\mathrm{e}}$ is the combination of lattice distortion and rigid rotation, and $\boldsymbol{F}_{\mathrm{p}}$ indicates plastic strain caused by the crystal slipping and twinning.

The elastic strain tensor can be obtained by the elastic deformation gradient:

$$
\boldsymbol{E}_{\mathrm{e}}=\left(\boldsymbol{F}_{\mathrm{e}}^{\mathrm{T}} \cdot \boldsymbol{F}_{\mathrm{e}}-\boldsymbol{I}\right) / 2 .
$$

The Second Piola-Kirchhoff Stress $\boldsymbol{T}_{\mathrm{e}}$ can be expressed:

$$
\begin{gathered}
\boldsymbol{T}_{\mathrm{e}}=\boldsymbol{F}_{\mathrm{e}}^{-1} \cdot\left\{\operatorname{det}\left(\boldsymbol{F}_{\mathrm{e}}\right) \boldsymbol{T}\right\} \cdot \boldsymbol{F}_{\mathrm{e}}^{-\mathrm{T}} \\
\boldsymbol{T}_{\mathrm{e}}=\boldsymbol{C}: \boldsymbol{E}_{\mathrm{e}} .
\end{gathered}
$$

According to the Schmid theorem, the shear stress of slip system is shown as follow:

$$
\tau_{\alpha}=\boldsymbol{T}_{\mathrm{e}}: \boldsymbol{S}_{\alpha} .
$$




\section{ICNFT 2015}

Whether the slip system is activated can be deduced from Eq. (5). $\dot{\gamma}_{\alpha}$ can be obtained directly by shear stress, and the indeterminacy caused by the activation judgment of slipping system can be avoided [11].

$$
\dot{\gamma}_{\alpha}=\dot{\gamma}_{0}\left|\tau_{\alpha} / s_{\alpha}\right|^{1 / m} \operatorname{sign}\left(\tau_{\alpha}\right)
$$

For twinning, the change rate of twin crystal volume fraction can be expressed as follow:

$$
\begin{cases}\dot{f}_{\beta}=\frac{\dot{\gamma}_{0}}{\gamma_{\beta}}\left(\frac{\tau_{\beta}}{s_{\beta}}\right)^{1 / m}, & \\ \dot{f}_{\beta}=0, & \tau_{\beta}>0 \\ \hline & \leq 0 .\end{cases}
$$

The microscopic mechanism of crystal plastic deformation process is simply described by the single crystal model. However, owning to the frequent application of polycrystal in practical engineering, the polycrystal model of TWIP steel through polycrystalline homogenization method based on the single crystal model was built in this paper.

\subsection{Polycrystal plasticity homogenization method}

With the finite element model of homogenization as a reference [12], a finite element represents a grain orientation is supposed, and the stress response of material particles is decided by the stress response of a single grain, thus the relationship between polycrystal and single crystal is built by using the finite element model of homogenization.

The deformation gradient of the polycrystalline material is shown as follow [13]:

$$
\overline{\boldsymbol{F}}=\nabla \overline{\boldsymbol{x} y} .
$$

And the deformation gradient $\overline{\boldsymbol{F}}$ can be disintegrated as:

$$
\overline{\boldsymbol{F}}=\overline{\boldsymbol{F}}_{\mathrm{e}} \cdot \overline{\boldsymbol{F}}_{\mathrm{p}} .
$$

Referring to the Ref. [14], the relationship between the second Piola-Kirchhoff stress and deformation gradient is shown in Eq. (10):

$$
\overline{\boldsymbol{T}}_{\mathrm{e}}=\overline{\boldsymbol{F}}_{\mathrm{e}}^{-1} \cdot\left\{\boldsymbol{\operatorname { d e t }}\left(\overline{\boldsymbol{F}}_{\mathrm{e}}\right) \overline{\boldsymbol{T}}\right\} \cdot \overline{\boldsymbol{F}}_{\mathrm{e}}^{-\boldsymbol{T}} .
$$

The relationship between the first Piola-Kirchhoff stress and second Piola-Kirchhoff stress is shown as:

$$
\overline{\boldsymbol{P}}=\overline{\boldsymbol{F}} \cdot \overline{\boldsymbol{T}_{\mathrm{e}}} .
$$

The deformation gradient is related to $\overline{\boldsymbol{P}}$ and the volume of polycrystal:

$$
\begin{gathered}
\overline{\boldsymbol{F}}=\frac{1}{V} \int_{\beta} \boldsymbol{F} \mathrm{d} V \\
\overline{\boldsymbol{P}}=\frac{1}{V} \int_{\beta} \boldsymbol{P} \mathrm{d} V \\
V=\int_{\beta} \mathrm{d} V .
\end{gathered}
$$

\subsection{The deep-drawing process based on CPFE model}

Based on the crystal plasticity constitutive model and parameters which have been determined for TWIP steel, a simplified finite element model for deep-drawing is built, and the earing-type characteristics in 

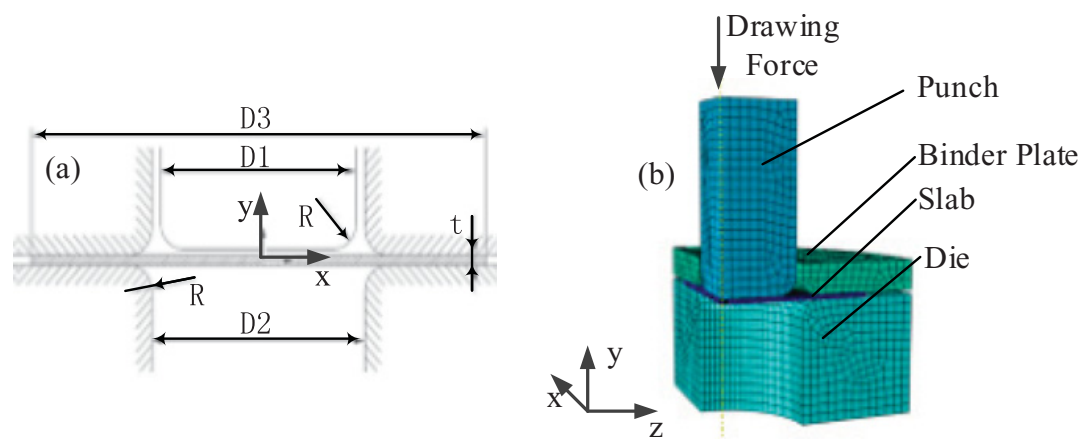

Figure 2. The schematic diagram of deep-drawing and finite element model (a) The schematic diagram of deepdrawing (b) Finite element model.

Table 1. The parameters of the deep-drawing model.

\begin{tabular}{c|c|c|c|c|c}
\hline parameters & $\begin{array}{c}\text { Diameter of } \\
\text { punch } \mathrm{D}_{1} / \mathrm{mm}\end{array}$ & $\begin{array}{c}\text { radius of fillet } \\
\mathrm{R} / \mathrm{mm}\end{array}$ & $\begin{array}{c}\text { Diameter of die } \\
\mathrm{D}_{2} / \mathrm{mm}\end{array}$ & $\begin{array}{c}\text { Diameter of billet } \\
\mathrm{D}_{3} / \mathrm{mm}\end{array}$ & $\begin{array}{c}\text { Thickness of } \\
\text { billet } \mathrm{t} / \mathrm{mm}\end{array}$ \\
\hline value & 50 & 6 & 54.32 & 80 & 1.47 \\
\hline parameters & $\begin{array}{c}\text { drawing } \\
\text { coefficient } \\
\mathrm{m}_{1}\end{array}$ & $\begin{array}{c}\text { friction coefficient } \\
\text { between punch } \\
\text { and billet }\end{array}$ & $\begin{array}{c}\text { friction coefficient } \\
\text { between billet and } \\
\text { die }\end{array}$ & $\begin{array}{c}\text { friction coefficient } \\
\text { between billet and } \\
\text { binder plate }\end{array}$ & $\begin{array}{c}\text { blank holder } \\
\text { force/kN }\end{array}$ \\
\hline value & 0.625 & 0 & 0.1 & 0.1 & 60 \\
\hline
\end{tabular}

typical deep-drawing process are simulated. The schematic diagram and finite element model are shown in Fig. 2, the parameters of the model is shown in Table 1.

Cartesian coordinates $(\mathrm{x}, \mathrm{y}, \mathrm{z})$ are used as shown in Fig. 2(b), the origin of the coordinates is set at the centre of the lower surface, and the centre line of the model is set as y axis. Considering the symmetrical characteristic of model, a quarter of the model is built, symmetry constraints are imposed on the left and front surface, and the lower surface of the die is fixed. The upper surface of the punch is subjected to the drawing forces and the punch can move along y axis only. To guarantee the convergence of calculation, C3D8 unit is adopted to the model. The friction coefficient between punch and billet is defined as 0 , and the friction coefficient between the billet and the die is 0.1 , it's the same between the billet and the binder plate.

\section{Results and discussion}

ABAQUS/UMAT is adopted to simulate the earing making process. As shown in Fig. 3(a), the strain of deep-drawing parts is different in all directions, which commendably describes the anisotropic behaviour of the material, and the formation of $6-0^{\circ} / 60^{\circ}$-earing-type reflects the advantage of CPFE in the earing making process.

When the drawing coefficient is taken as $0.5,0.625$ and 0.714 , the earing is shown in Fig. $4.6-0^{\circ} / 60^{\circ}$ earing-type are produced in all three working conditions. Earing-type doesn't change under different drawing coefficient, so the drawing coefficient doesn't influence the earing-type, which is consistent with Ref. [15]. The earing ratio is respectively $6.5 \%, 8.44 \%$ and $14.2 \%$, which increase with the decrease of drawing coefficient.

The drawing forces are shown in Fig. 5, in which (a) shows the drawing forces under different displacement of punch, and (b) shows the earing ratio and peak drawing forces under different drawing coefficient. Figure 5 shows that, the drawing forces peaks when the punch moves half of the travel, and 


\section{ICNFT 2015}

LE, Max. Principal (Avg: $75 \%$ )
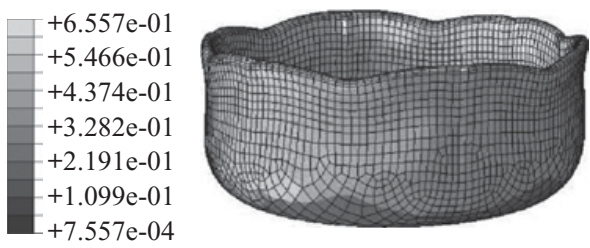

(a)

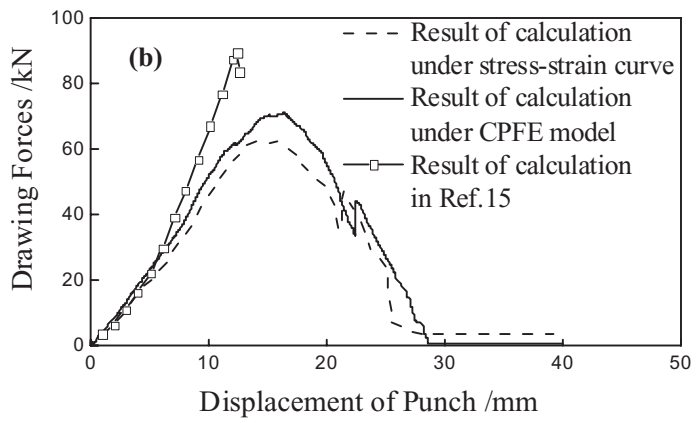

Figure 3. Calculation results of CPFE model (a) result of CPFE model (b) drawing forces curve.

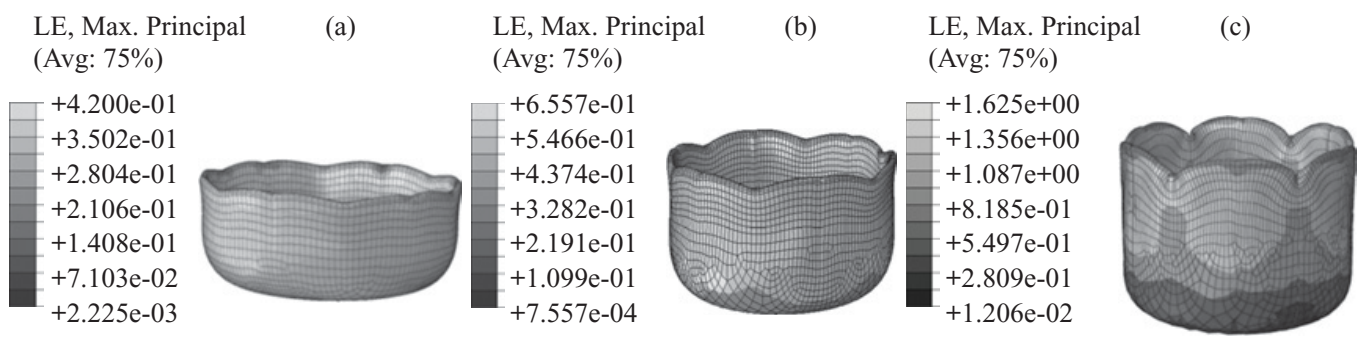

Figure 4. Results of CPFE model under different drawing coefficients (a) $\mathrm{m}_{1}=0.714$ (b) $\mathrm{m}_{1}=0.625$ (c) $\mathrm{m}_{1}=0.5$.
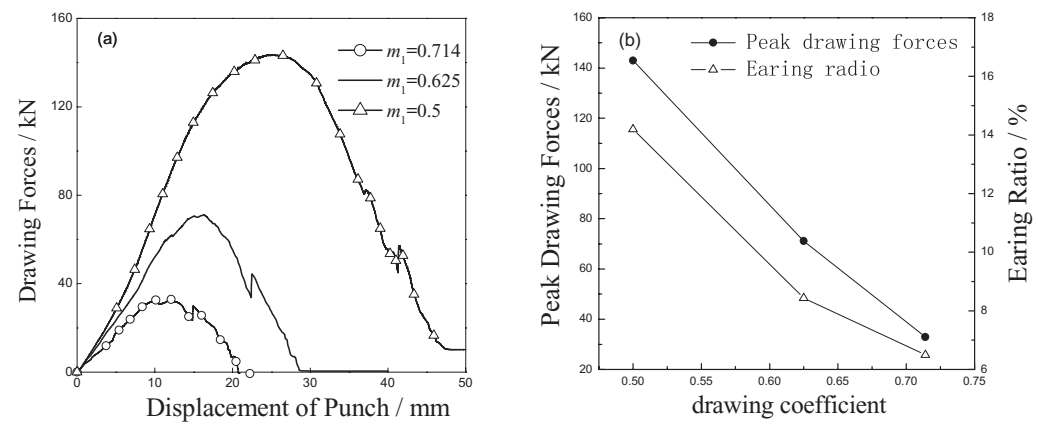

Figure 5. Drawing forces curve and earing ratio curve under different drawing coefficients (a) drawing forces displacement curve (b) earing ratio and peak drawing forces.

the peak drawing forces increase with the decrease of drawing coefficient. It can be inferred that the peak drawing forces and the earing ratio are both negatively correlated with drawing coefficient.

Earing formation lies in the material anisotropy caused by the texture, so the effect of initial texture on earing is important, which is shown in Fig. 6 and Fig. 7. The main types of initial texture are the brass type $\{011\}\langle 211\rangle$, cubic type $\{001\}\langle 100\rangle$ and Gauss type $\{011\}\langle 100\rangle$. As Fig. 6 shows, under the three types of initial texture, the earing-types are different from each other. Under the brass type of initial texture, there are $6-0^{\circ} / 60^{\circ}$-earing-type, and the earing ratio is $8.44 \%$; Under the cubic type, there are $4-0^{\circ} / 90^{\circ}$-earing-types, and the earing ratio is $13 \%$. There are $4-0^{\circ} / 90^{\circ}$-earing-types under the Gauss type, and the earing ratio is $17.4 \%$. 


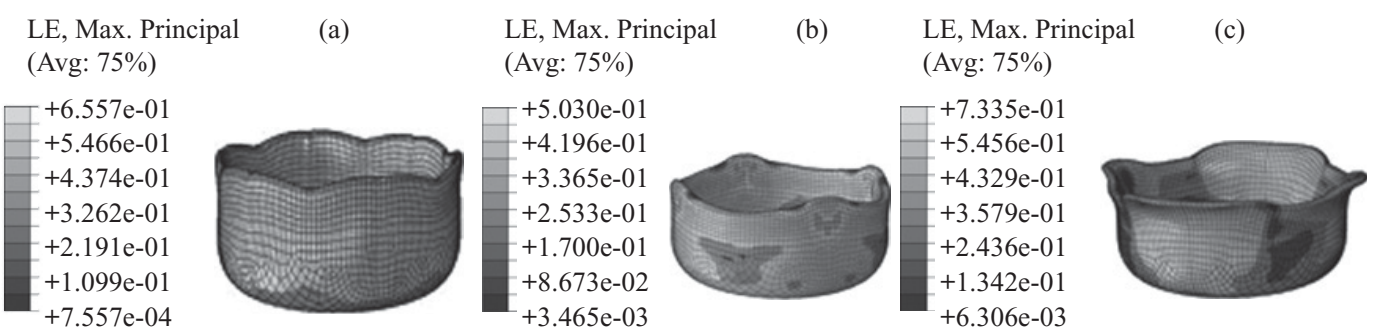

Figure 6. Results of CPFE model under different initial texture (a) brass type (b) cubic type (c) Gauss type.

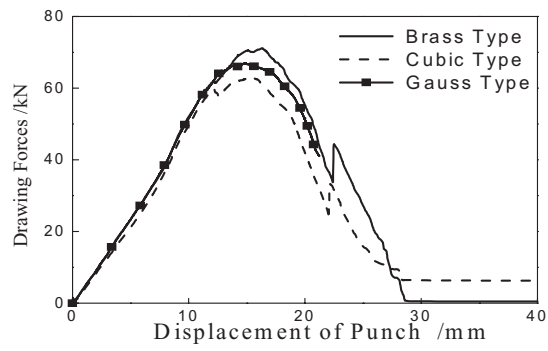

Figure 7. Drawing forces under different initial texture.

The drawing forces are shown in Fig. 7, and the peak drawing forces are about $65 \mathrm{kN}$ under all the three types of initial texture. Therefore, the earing-type of TWIP steel depends on the initial texture, and the earing ratio varies a lot under different initial texture, while the initial texture does not affect the force so much.

\section{Conclusions}

In this paper, the crystal plasticity constitutive relation of single crystal and polycrystal is deduced, which are used to built the CPFE model of the earing making process, in addition, the impacts of drawing coefficient and initial texture on the earing characteristics are discussed, the conclusions are listed as follows:

(1) The plasticity constitutive model is built, and through the simulation of slipping and twinning, the effect of slipping coupled twinning is shown at micro-level.

(2) Depending on the result of the CPFE model, when the drawing coefficient is taken as $0.5,0.625$ and 0.714 , the earing ratios are respectively $14.2 \%, 8.44 \%$ and $6.5 \%$, and the peak drawing forces are respectively $143 \mathrm{kN}, 71.1 \mathrm{kN}$ and $32.9 \mathrm{kN}$, they are both negatively correlated with drawing coefficient.

(3) The earing-type of TWIP steel depends on the initial texture, and the earing ratio varies a lot under different initial texture, while the initial texture does not affect the drawing force so much.

The authors would like to thank the financial support to this research from the National Natural Science Foundation of China (No. 51105029), NSAF (No. U1330121), Opening fund of State Key Laboratory of Nonlinear Mechanics (No.LNM201512), the Beijing Science Foundation of China (No. 3112019), and the Doctoral Fund of Ministry of Education of China (No. 20100006120013). 


\section{References}

[1] T. Senuma, ISIJ Int, 41, 520 (2001)

[2] O. Grassel, G. Frommeyer, J Mater Sci Technol, 14, 1213 (1998)

[3] I. Gutierrez-Urrutia, D. Raabe. Acta Mater, 59, 6449 (2011)

[4] C.Y. Sun, J. Huang, N. Guo, J. Yang, Acta Metall Sin, 9, 1115 (2014)

[5] D. Babier, V. Favier, B. Bolle, Mat Sci Eng A, 540, 212 (2012)

[6] G.I. Taylor, J Jpn Inst Met, 62, 307 (1938)

[7] P.V. Houtte, Acta Metall, 26, 591 (1978)

[8] S.R. Kalidindi, Int J Plast, 17, 837 (2001)

[9] A.A. Salem, S.R. Kalidindi, S.L. Semiatin, Acta Mater, 53, 3495 (2005)

[10] S.R. Kalidindi, J Mech Phys Solids, 46, 267 (1998)

[11] P. Van Houtte, S. Li, M. Seefeldt, L. Delannay, Int J Plast, 21, 589 (2005)

[12] F. Roters, P. Eisenlohr, L. Hantcherli, et al, Acta Mater, 58, 1152 (2010)

[13] D. Raabe, R.C. Becker, Model Simul Mater Sci Eng, 8, 445 (2000)

[14] C.Y. Sun, X.R. Guo, J. Huang, N. Guo, S.W. Wang, J. Yang, Acta Metall Sin, 3, 357 (2015)

[15] Y. Huang, A.M. Zhao, Z.L. Mi, et al, J Iron Steel Res Int, 20, 111 (2013) 